Polymer Journal, Vol. 39, No. 9, pp. 928-934 (2007)

(C) 2007 The Society of Polymer Science, Japan

\title{
Chain Conformation Effects on Molecular Motions at the Surface of Poly(methyl methacrylate) Films
}

\author{
Yoshihisa FuJII, Kei-ichi AKABORI, Keiji TANAKA, ${ }^{\dagger}$ and Toshihiko NAGAmURA ${ }^{\dagger}$ \\ Department of Applied Chemistry, Faculty of Engineering, Kyushu University, \\ 744 Motooka, Nishi-ku, Fukuoka 819-0395, Japan
}

(Received March 22, 2007; Accepted May 22, 2007; Published July 10, 2007)

\begin{abstract}
Surface relaxation in syndiotactic (st-) and isotactic (it-) poly(methyl methacrylate) (PMMA) films was studied by lateral force microscopy. The $\alpha_{\mathrm{a}}$ - and $\beta$-relaxation processes were clearly observed even at the surface, permitting us to deduce the form of the dispersion map for the surface relaxation processes. Both relaxation temperatures at the surface were lower than the corresponding ones in the bulk. In addition, the extent to which the peak temperature for the surface relaxation processes fell below that of the bulk strongly depended on the stereoregularity of the films. The differences in the chain conformations between the surface and the bulk, which were more remarkable in the $s t$-PMMA, produced this variation in surface mobility. [doi:10.1295/polymj.PJ2006270]

KEY WORDS Surface Relaxation / Poly(methyl methacrylate) / Tacticity /
\end{abstract}

In the last decade, the surface structure and physical properties of polymeric solids have been extensively studied because of both their technological importance and inherent scientific interest. ${ }^{1-3}$ The consistent conclusion obtained thus far is that mobility at the surface is generally enhanced in comparison with the bulk, ${ }^{4-31}$ though there are controversial arguments against the enhanced surface dynamics. ${ }^{32-35}$ This difference in mobility has been tentatively explained in terms of chain end segregation, reduced cooperativity, loosened entanglement, and chain orientation at the surface. However, these factors were obtained on the basis of experiments mainly using atactic polystyrene (PS). Thus, to understand why this peculiar mobility should appear at the surface, investigators should systematically study the surface mobility of other polymers.

In this study of surface molecular motion, we have chosen poly(methyl methacrylate) (PMMA) for several reasons. PMMA exhibits two relaxation processes $\left(\alpha_{\mathrm{a}}\right.$ and $\left.\beta\right)$ in the temperature region of 200 to $400 \mathrm{~K}$ which can be accessed by our experimental technique, lateral force microscopy (LFM). First, we wish to determine whether the $\alpha_{\mathrm{a}}$-relaxation process corresponding to the segmental motion is also faster at the surface than in the bulk for PMMA. And, if so, by how much? Second, what is the effect on the $\beta$-relaxation process at the surface, which is assigned to a relatively smaller molecular motion? ${ }^{36}$ Third, how does the sequential structure of the polymer affect the surface molecular motion? Since stereoregular PSs form a crystalline phase, a study of the tacticity effect for PS is not simple. On the other hand, with the choice of appropriate preparation conditions, stereoregular PMMAs can be made amorphous by freezing. Finally, the molecular motion of PMMA has been reported in thin films ${ }^{26,37-42}$ and at the interface with solid substrates $^{43-46}$ using other techniques. Therefore, to aid our understanding of the molecular motion of PMMA in confined systems, we can compare the surface molecular motion of PMMA as determined by LFM with these results.

\section{EXPERIMENTAL}

The $s t$ - and it-PMMA used in this study were purchased from Polymer Laboratories Ltd. and Polymer Source Inc., respectively. Table I shows the samples' number-average molecular weight $\left(M_{\mathrm{n}}\right)$ and molecular weight distribution $\left(M_{\mathrm{w}} / M_{\mathrm{n}}\right)$, where $M_{\mathrm{w}}$ is the weightaverage molecular weight. The triad contents were determined by ${ }^{13} \mathrm{C}$ nuclear magnetic resonance (NMR, JNM-ECP400, JEOL Ltd.) spectroscopy. Although the $r r$ triad content of the $s t$-PMMA was not particularly high, the value was good enough to lend the sample a syndiotactic character. ${ }^{47,48}$ The bulk glass transition temperature $\left(T_{\mathrm{g}} \mathrm{b}\right)$ was determined by differential scanning calorimetry (DSC220, SII NanoTechnology Inc.) at a heating rate of $10 \mathrm{~K} \cdot \mathrm{min}^{-1}$ under a dry nitrogen purge. Films of the PMMA were spin-coated from toluene solutions onto silicon wafers with native oxide layers. The films were dried under the ambient atmosphere at room temperature for more than $24 \mathrm{~h}$, and then annealed under vacuum at $423 \mathrm{~K}$ for $24 \mathrm{~h}$. The film thickness, evaluated by ellipsometry (M-150, JASCO Co., Ltd.), was approximately $460 \mathrm{~nm}$, which

${ }^{\dagger}$ To whom correspondence should be addressed (Tel: +81-92-802-2879 (KT) and +81-92-802-2878 (TN), Fax: +81-92-802-2880, E-mail: k-tanaka@cstf.kyushu-u.ac.jp (KT), nagamura@cstf.kyushu-u.ac.jp (TN)). 
Table I. Characterization of the PMMA used in this study

\begin{tabular}{lcccccc}
\hline & \multirow{2}{*}{$M_{\mathrm{n}}$} & \multirow{2}{*}{$M_{\mathrm{w}} / M_{\mathrm{n}}$} & \multirow{2}{*}{$T_{\mathrm{g}}^{\mathrm{b}} / \mathrm{K}$} & \multicolumn{3}{c}{ tacticity (\% triads) } \\
\cline { 5 - 7 } & & & & $\mathrm{mm}$ & $\mathrm{mr}$ & $\mathrm{rr}$ \\
\hline st-PMMA & $1.58 \mathrm{M}$ & 1.07 & 395 & 3 & 40 & 57 \\
it-PMMA & $610 \mathrm{k}$ & 1.22 & 326 & $99>$ & & \\
\hline
\end{tabular}

was sufficient to avoid any ultrathinning effects on the surface molecular motion. ${ }^{2,31}$

The surface relaxation behavior of the PMMA films was examined by LFM (SPA300HV, SII NanoTechnology Inc.) with an SPI3800 controller. The LFM measurement was carried out under vacuum, thus avoiding the effects of surface oxidation and capillary force induced by surface adsorbed water. The cantilever used was made from $\mathrm{Si}_{3} \mathrm{~N}_{4}$, of which both sides were uncoated. Its spring constant was estimated to be $c a .0 .1 \mathrm{~N} \cdot \mathrm{m}^{-1}$ and the tip radius of curvature was typically less than $20 \mathrm{~nm}$. The normal force onto the cantilever was set to be approximately $10 \mathrm{nN}$. The lateral force was obtained in a line scan mode. The line position on the surface was randomly changed after each scan so as to minimize surface damage induced by contact with the tip. We confirmed by standard atomic force microscopic imaging that the LFM measurements did not introduce any damage at the surface. Each data point for a lateral force presented in Figures 1 and 2 was the average of more than one hundred individual values. For the temperaturedependent measurements at a given scanning rate, the heating rate was $0.4 \mathrm{~K} \cdot \mathrm{min}^{-1}$. We also conducted a dynamic mechanical analysis of the bulk PMMA samples with a Rheovibron instrument (DDV-01FP, A\&D Co., Ltd.) in order to provide a direct comparison of the surface relaxation behavior with that of the bulk.

To examine the surface aggregation states, we measured the static contact angle for the PMMA films at $297 \mathrm{~K}$ (DSA-10, Krüss Co., Ltd.). As a probe liquid, pure water with an initial resistivity greater than $18 \mathrm{M} \Omega$ after purification by a Milli-QII system (Millipore Co., Ltd.) was used. In addition, we analyzed the PMMA films with an attenuated total reflection Fourier transform infrared (ATR-FT/IR) spectroscopy with a $\mathrm{Ge}$ or $\mathrm{ZnSe}$ prism as the internal reflection element. The spectra were recorded at a resolution of $0.5 \mathrm{~cm}^{-1}$ with a Herschel FT/IR-620 spectrometer (JASCO Co., Ltd.); 1024 scans were needed to obtain spectra with high signal-to-noise ratios.

\section{RESULTS AND DISCUSSION}

In general, the frictional behavior of polymeric solids is closely related to their viscoelastic properties. ${ }^{49,50}$ Hence, it is possible to study the surface

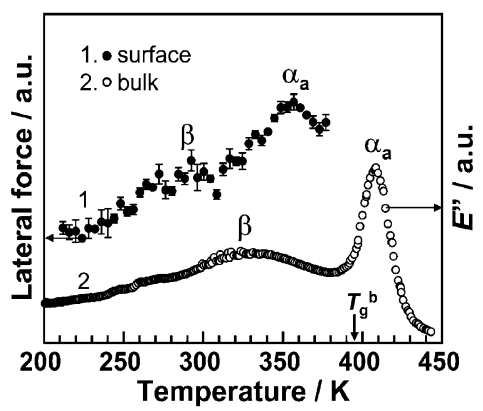

Figure 1. Temperature dependence of lateral force at a scanning rate of $1 \mu \mathrm{m} \cdot \mathrm{s}^{-1}$ and dynamic loss modulus $\left(E^{\prime \prime}\right)$ at a frequency of $70 \mathrm{~Hz}$ for the st-PMMA.

relaxation of polymeric films by LFM. ${ }^{5,51}$ Figure 1 shows the temperature dependence of the lateral force at the scanning rate of $1 \mu \mathrm{m} \cdot \mathrm{s}^{-1}$ for a st-PMMA film. For comparison, the dynamic loss modulus $\left(E^{\prime \prime}\right)$ at a frequency of $70 \mathrm{~Hz}$ for the bulk sample is also shown. In the case of the bulk, two relaxation peaks were observed. The sharper one on the higher temperature side, arising from the segmental motion, is called the $\alpha_{\mathrm{a}}$-relaxation. ${ }^{36}$ The onset temperature of the peak near this frequency of $70 \mathrm{~Hz}$ is empirically found to be close to the $T_{\mathrm{g}}^{\mathrm{b}}$, and, as shown in Figure 1, such was the case for the current work. The broader peak on the lower temperature side can be assigned to a $\beta$-relaxation process related to the hindered rotation of a $-\mathrm{COOCH}_{3}$ group about the C-C bond which links it to the main part of the chain. ${ }^{36}$ Since the LFM scanning rate of $1 \mu \mathrm{m} \cdot \mathrm{s}^{-1}$ is simply converted to a deformation frequency of approximately $66 \mathrm{~Hz},{ }^{51}$ the surface and bulk data presented in Figure 1 can be directly compared.

The $\alpha_{\mathrm{a}^{-}}$and $\beta$-relaxation processes could be seen even at the film surface. The relaxation processes at the surface overlapped each other, and thus, the $\beta$ process appeared as a shoulder rather than a peak. In addition, the surface relaxation processes were observed at temperatures lower than those for the corresponding ones in the bulk. Evidently, the molecular motion at the surface is thermally more vigorous than that in the bulk. Assuming that the onset temperature of the surface $\alpha_{\mathrm{a}}$-process, at which the lateral force starts to increase at $1 \mu \mathrm{m} \cdot \mathrm{s}^{-1}$, corresponds to the $T_{\mathrm{g}} \mathrm{s}, 5$ we estimate that temperature to be roughly $320 \mathrm{~K}$. Although the overlapping of the $\alpha_{\mathrm{a}^{-}}$and $\beta$-relaxation processes impedes a quantitative discussion related to the $T_{\mathrm{g}} \mathrm{s}, 52$ it is plausible that the depression of the $T_{\mathrm{g}}$ at the surface, relative to the bulk value of $395 \mathrm{~K}$, is approximately $75 \mathrm{~K}$ for the $s t$-PMMA film. Such a huge $T_{\mathrm{g}}$ reduction at the surface has never been seen for a PS with a comparable molecular weight. ${ }^{5}$ This trend is opposite to the thinning-induced $T_{\mathrm{g}}$ reduction seen in PMMA and PS films: the $T_{\mathrm{g}}$ reduction 


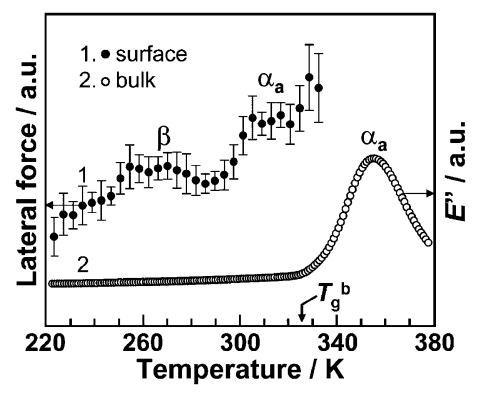

Figure 2. Temperature dependence of lateral force and $E^{\prime \prime}$ for the $i t$-PMMA. The scanning rate of $1 \mu \mathrm{m} \cdot \mathrm{s}^{-1}$ in the LFM measurement is comparable to the frequency of $70 \mathrm{~Hz}$ in the bulk measurement.

induced by the thinning effect for PS films is much larger than that for films of PMMA. ${ }^{22,23,26,37,41,42}$

It is known that in the case of bulk PMMA, molecular motion is strongly affected by its sequential structure, specifically, its tacticity. ${ }^{36}$ Hence, we measured an it-PMMA film by LFM to clarify the effect of tacticity on the surface molecular motion. Although itPMMA chains can form a crystalline structure, a wide angle X-ray diffraction measurement revealed that the chains in the films, prepared by a procedure stated in the experimental section, were in an amorphous state. Figure 2 shows the temperature dependence of the lateral force and the bulk $E^{\prime \prime}$ for the it-PMMA. In the case of the bulk, the $\beta$-relaxation process was not observed at a frequency of $70 \mathrm{~Hz}$. Since it was detectable at lower frequencies (not shown), it probably overlapped with $\alpha_{\mathrm{a}}$-process at the frequency of $70 \mathrm{~Hz}$. In contrast, both the $\alpha_{\mathrm{a}^{-}}$and $\beta$-relaxation processes were clearly seen at the surface; again, the observed temperature regions were lower than those for the corresponding bulk relaxation processes. However, for the $i t$-PMMA, the difference in $\alpha_{\mathrm{a}}$-relaxation temperature between the surface and the bulk was only $25 \mathrm{~K}$, a discrepancy much smaller than that for the stPMMA. This possibly indicates that the tacticity exerts a greater effect on the surface molecular motion in the PMMA films.

In addition, a comparison of the surface molecular motion in PMMA and PS is worthwhile. In the case of PS, the $T_{\mathrm{g}}$ depression at the surface was approximately $20-25 \mathrm{~K}$ for a higher $M_{\mathrm{n}}$ sample. ${ }^{5}$ This finding is in good agreement with the results obtained here for the it-PMMA, which also possesses a high $M_{\mathrm{n}}$. Thus, this $T_{\mathrm{g}}$ reduction at the surface exhibited by the itPMMA might be explained by the same arguments mentioned in the introduction for PS. Interestingly, for the it-PMMA, the surface $\beta$-relaxation temperature was also lower than that of the corresponding bulk process, although, as shown in Figure 2, the bulk $\beta$ process cannot clearly be seen at the frequency of $70 \mathrm{~Hz} .{ }^{53}$ Kremer and co-workers, using dielectric re- laxation spectroscopy, have systematically studied how the $\alpha_{\mathrm{a}}$ - and $\beta$-processes for the it-PMMA depend on the film thickness, and have reported that the $\beta$ process remains unchanged with decreasing thickness. ${ }^{40}$ Thus, in the case of it-PMMA, Kremer's results indicate that the $\beta$-process is insensitive to a change in the microenvironment. In general, it is hard to reproduce the reported physical properties of stereoregular PMMA, because they are easily influenced by the chain sequence, the presence of microcrystallites and so forth. Thus, in the near future, we will examine the surface $\beta$-process using $i t$-PMMA with various sequences, so that we can discuss why our result is inconsistent with their findings. And, at the same time, we will describe our dynamic mechanical analy$\mathrm{sis}^{31}$ for the $i t$-PMMA thin films.

In order to clarify the difference in mobility between the surface and the bulk quantitatively, we next discuss the scanning rate dependence of the lateral force at a given temperature, so that we can uncover the apparent activation energy for each surface relaxation process. Since, as can be seen in Figure 2, the relaxation peaks for the it-PMMA were too ambiguous to accurately determine the positions of the maxima, we restricted further investigations to the stPMMA sample. Figure 3 shows the typical scanning rate dependence of the lateral force in the temperature range from 355 to $369 \mathrm{~K}$ for the st-PMMA. The scanning rate at which the $\alpha_{\mathrm{a}}$-relaxation peak was observed shifted to higher values with rising temperature. A dependence of the lateral force on scanning rate was also observed for the $\beta$-process. Thus, these are clear signatures indicating that the peak and shoulder are truly related to the relaxation processes.

Figure 4 shows the locations in temperature and frequency for the $\alpha_{\mathrm{a}}$ - and $\beta$-relaxation processes in the st-PMMA films, converted from the scanning rate. The open and closed symbols denote the surface and

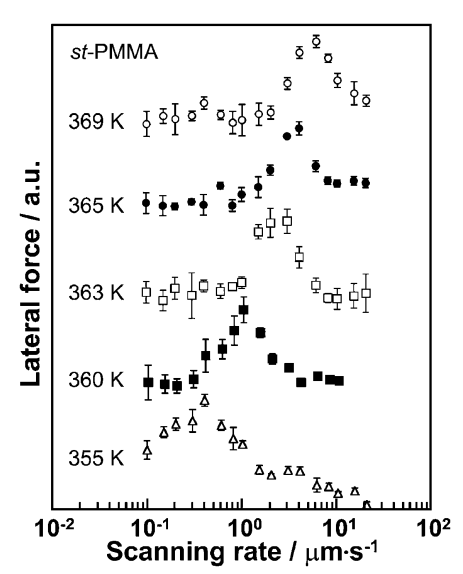

Figure 3. Scanning rate versus lateral force as a function of temperature for the surface $\alpha_{\mathrm{a}}$-relaxation in the st-PMMA film. 


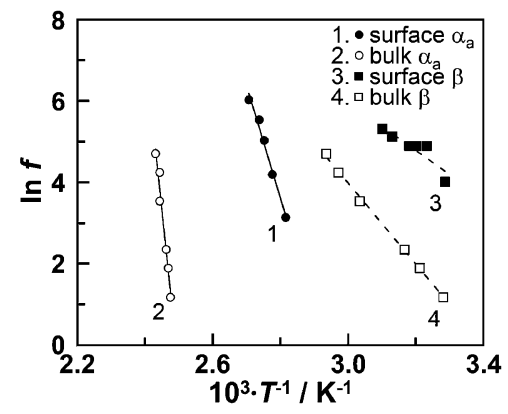

Figure 4. Frequency and temperature locations of mechanical loss maxima at the surface and in the bulk for the st-PMMA.

the bulk data, respectively. Since the relation between $(\ln f)$ and $T^{-1}$ seemed to be linear, at least within the temperature region employed, the following equation was applied to extract the apparent activation energy $\left(\Delta H^{*}\right)$ for the surface relaxation processes:

$$
\Delta H^{*}=-R \cdot d(\ln f) / d T
$$

where $R$ is the gas constant. The $\Delta H^{*}$ value for the surface $\alpha_{\mathrm{a}}$-process was estimated to be $230 \pm 20$ $\mathrm{kJ} \cdot \mathrm{mol}^{-1}$, which was much lower than the corresponding bulk value of $660 \pm 60 \mathrm{~kJ} \cdot \mathrm{mol}^{-1}$. This difference should reflect the discrepancy in cooperativity in the segmental motion, resulting from the fact that the segments existing in the surface region have fewer neighbors than those in the interior region. ${ }^{5,24} \mathrm{~A}$ similar linear relation was observed for the $\beta$-relaxation process for both the surface and the bulk, and their respective $\Delta H^{*}$ values were estimated to be $50 \pm 10$ and $80 \pm 2 \mathrm{~kJ} \cdot \mathrm{mol}^{-1}$. Thus, the $\beta$-process might also be activated at the surface. However, molecular motion on a relatively small scale is widely accepted to be generally insensitive to a change in the microenvironment. ${ }^{36}$ On the other hand, a recent two-dimensional nuclear magnetic resonance spectroscopic study has revealed that $\beta$-relaxation is a complicated process composed of a hindered rotation of side chain groups and local cooperative movement. ${ }^{54}$ If this is the case at the surface, the activation for the $\beta$-relaxation process there can be easily understood. Fukao et al. have used dielectric relaxation spectroscopy to examine $\alpha_{\mathrm{a}^{-}}$and $\beta$-relaxation processes in ultrathin films of PMMA. ${ }^{39}$ They have claimed that once the thickness became smaller than a critical value around $100 \mathrm{~nm}$, the relaxation temperature for the $\alpha_{\mathrm{a}}$ - and the $\beta$-processes decreased with decreasing thickness. Our findings are essentially consistent with their results.

Ngai et al. proposed the coupling model (CM) to explain the general relationship between the $\alpha_{\mathrm{a}}$ - and the $\beta$-relaxation processes. ${ }^{24}$ According to this model, a coupling parameter $(n)$, which depends on the chemical structure, molecular weight, tacticity, and confinement, is given by

$$
n=\left\langle\log \left(\tau_{\alpha}\right)-\log \left(\tau_{\beta}\right)\right\rangle /\left\langle 11.7+\log \left(\tau_{\alpha}\right)\right\rangle
$$

where $\tau_{\alpha}$ and $\tau_{\beta}$ are the relaxation times for the $\alpha_{\mathrm{a}^{-}}$ and the $\beta$-processes, respectively. The physical meaning of the $n$ value quantifies the intermolecular interaction among neighboring segments. Assuming that $\tau_{\alpha}$ and $\tau_{\beta}$ at $T_{\mathrm{g}}$ are respectively equal to $100 \mathrm{~s}$ and $1 /(2 \pi f)$, where $f$ is extrapolated from the Arrhenius relation data in Figure 4, we can estimate the $n$ values at the surface and in the bulk of the st-PMMA. The $n$ values so obtained were 0.38 and 0.48 for the surface and the bulk, respectively. Thus, it seems reasonable to conclude that the size or the energy barrier to the cooperative motion at the surface is much smaller than that in its internal bulk state due to less intermolecular interactions among the segments at the surface. A reduction in the cooperativity at the surface might arise from the existence of free space on the polymer surface.

Next, we consider the notable depression of the $\alpha_{\mathrm{a}^{-}}$ relaxation temperature for the st-PMMA film. The molecular motion of the st-PMMA was much more vigorous than that of the it-PMMA. The following discussion provides a rationale. Recall from Table I that the $T_{\mathrm{g}} \mathrm{b}$ of the $i t$-PMMA was much lower than that of the st-PMMA. Thus, if the $i t$-sequences in the stPMMA film were preferentially segregated at the surface, the mechanism for this surface activation can be easily understood. To confirm this suggestion, we carried out a contact angle measurement for the stPMMA with water as the probe liquid. ${ }^{48}$ Tretinnikov has reported that the water contact angles for films of $s t$-PMMA with a $r r$ content of $93 \%$ and $i t$-PMMA with a $\mathrm{mm}$ content of $91 \%$ were 79.5 and 66.5 degrees, respectively. ${ }^{48}$ In the case of the $s t$-PMMA used here, the $r r$ content was $57 \%$ and the water contact angle was $75.7 \mathrm{deg}$. This result means that the $r r$ content, in particular, the $s t$-sequences, were enriched at the surface. Thus, an explanation based on the surface segregation of it-sequences should be rejected. ${ }^{48}$

Next we consider the chain conformation at the surface. In the bulk region of the st-PMMA, the transtrans conformation is dominant over the trans-gauche, due to a dipole-dipole interaction between the side chains ${ }^{55,56}$ In contrast, it-PMMA lacks such a strong interaction between side chains. This, then, is the origin of the $T_{\mathrm{g}} \mathrm{b}$ difference between the st- and itPMMA. ${ }^{56,57}$ In other words, the presence of the dipole-dipole interaction between side chains creates the higher $T_{\mathrm{g}}$. Therefore, if a geometrical restriction prohibits the trans-trans conformation at the surface of the st-PMMA, the molecular motion at the surface might be enhanced on that basis alone, without any other factors being responsible. To examine this assumption, we performed an ATR-FT/IR measurement 


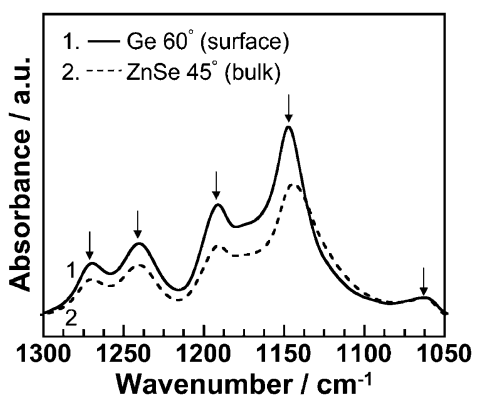

Figure 5. ATR-FT/IR spectra in the $1050-1300 \mathrm{~cm}^{-1}$ region of the st-PMMA films.

on the st-PMMA film, using Ge or $\mathrm{ZnSe}$ as an internal reflectance element. Figure 5 shows the spectra so obtained. The solid and dotted curves shown represent those obtained with $\mathrm{Ge}$ at an incident angle of $60^{\circ}$ and with $\mathrm{ZnSe}$ at an incident angle of $45^{\circ}$. The penetration depths of the evanescent waves were calculated to be $440 \mathrm{~nm}$ and $1.7 \mu \mathrm{m}$ for the main peak at 1150 $\mathrm{cm}^{-1}{ }^{55}$ Since the penetration depth of $1.7 \mu \mathrm{m}$ is much larger than the film thickness, the spectrum obtained with $\mathrm{ZnSe}$ is labeled as the bulk. Of course, the depth of $440 \mathrm{~nm}$ is huge in comparison with the depth range of the tip indentation for the LFM. However, taking into account that the electric field intensity becomes the strongest at the outermost surface and exponentially decays with increasing depth, it seems reasonable to consider that the spectrum obtained with Ge better reflects the conformation of the PMMA chains in the surface region than does that with $\mathrm{ZnSe}$.

The absorption peaks appeared at 1195, 1150 and $1060 \mathrm{~cm}^{-1}$ are assigned to the C-O-C asymmetric stretching vibration, the $\mathrm{C}-\mathrm{O}$ stretching vibration coupled with the skeletal $\mathrm{C}-\mathrm{C}$ vibration and the independent skeletal C-C stretching vibration, respectively. ${ }^{55,56,58}$ Also, both of the peaks at 1270 and 1240 $\mathrm{cm}^{-1}$ are ascribed to the C-C-O asymmetric stretching vibrations. ${ }^{55,56,58}$ The $1150 \mathrm{~cm}^{-1}$ peak consists of two superimposed elementary bands, such as trans-trans and trans-gauche backbone conformations, and the absorptivity of the trans-gauche band is higher than that of the trans-trans band. ${ }^{55}$ While the absorption peak at $1065 \mathrm{~cm}^{-1}$ is insensitive to the backbone conformation, that near $1150 \mathrm{~cm}^{-1}$ is quite sensitive to the tacticity of the PMMA. ${ }^{56}$ For example, the peak wavenumber shifts to a higher position with an increasing $s t$-sequence. In the case of the st-PMMA film, the surface content of the $s t$-sequences was higher than that of the bulk, as mentioned in the discussion of the water contact angle measurement results. Hence, the peak wavenumber should be shifted higher in the surface region; this is actually what was observed and is depicted in Figure 5. Since the absorption peak at $1150 \mathrm{~cm}^{-1}$ was larger in the surface spectrum than in the bulk one, it is conceivable that very little of the trans-trans conformation is formed closer to the surface, even for the $s t$-PMMA. Therefore, the $T_{\mathrm{g}}$ depression at the surface was more noticeable in the $s t$ PMMA film than in the it-PMMA. A strong correlation between the chain conformation and the $T_{\mathrm{g}}$ for stereoregular PMMAs has been also observed at the aluminum and $\mathrm{SiO}_{\mathrm{x}}$ interfaces. ${ }^{44}$ Grohens et al. have clearly shown that the interfacial $T_{\mathrm{g}}$, which we can equate to the $T_{\mathrm{g}}$ of an ultrathin film, can either increase or decrease, depending on the extent of the interaction between a side chain and the substrate, and that such a trend is strongly influenced by the tacticity of the sample. ${ }^{44}$ Our suggestions concerning the relationship between conformation and mobility at the surface of our samples are essentially the same as their findings at the corresponding interface.

\section{CONCLUSIONS}

This paper presents our LFM studies on surface $\alpha_{\mathrm{a}}{ }^{-}$ and $\beta$-relaxation processes in stereoregular PMMA films. At any given frequency, the surface relaxation temperatures for both processes were lower than the corresponding bulk ones. Both the st- and it-PMMAs exhibited this behavior, although the extent was very different in the two. The striking $T_{\mathrm{g}}$ depression at the film surface for the st-PMMA could be explained in terms of a discrepancy in the degree of chain conformation between surface and bulk.

Acknowledgment. This research was partly supported by Industrial Technology Research Grant Program in 2006 from New Energy and Industrial Technology Development Organization (NEDO) of Japan, and by the Grant-in-Aids for Young Scientists A (No. 18685014) and Science Research in a Priority Area "Soft Matter Physics" (No. 19031021) from the Ministry of Education, Culture, Sports, Science and Technology, Japan.

\section{REFERENCES}

1. F. Garbassi, M. Morra, and E. Occhiello, in "Polymer Surfaces from Physics to Technology," John Wiley \& Sons, Chichester, 1998.

2. R. A. L. Jones and R. W. Richards, in "Polymers at Surfaces and Interfaces," Cambridge University Press, Cambridge, 1999.

3. J. A. Forrest and R. A. L. Jones, in "Polymer Surfaces, Interfaces and Thin Films," A. Karim and S. Kumar, Ed., World Scientific, Singapore, 2000.

4. G. F. Meyers, B. M. DeKoven, and J. T. Seitz, Langmuir, 8, 2330 (1992).

5. a) T. Kajiyama, K. Tanaka, I. Ohki, S. R. Ge, J. S. Yoon, and A. Takahara, Macromolecules, 27, 7932 (1994). 
b) K. Tanaka, A. Taura, S. R. Ge, A. Takahara, and T. Kajiyama, Macromolecules, 29, 3040 (1996).

c) K. Tanaka, A. Takahara, and T. Kajiyama, Macromolecules, 33, 7588 (2000).

d) K. Tanaka, K. Hashimoto, T. Kajiyama, and A. Takahara, Langmuir, 19, 6573 (2003).

6. A. M. Mayes, Macromolecules, 27, 3114 (1994).

7. G. B. DeMaggio, W. E. Frieze, D. W. Gidley, M. Zhu, H. A. Hristov, and A. F. Yee, Phys. Rev. Lett., 78, 1524 (1997).

8. Y. C. Jean, R. Zhang, H. Cao, J. P. Yuan, C. M. Huang, B. Nielsen, and P. Asoka-Kumar, Phys. Rev. B, 56, R8459 (1997).

9. a) Y. M. Boiko and R. E. Prud'homme, J. Polym. Sci., Part B: Polym. Phys., 36, 567 (1998).

b) G. Guérin, F. Mauger, and R. E. Prud'homme, Polymer, 44, 7477 (2003).

c) Y. M. Boiko and R. E. Prud'homme, J. Macromol. Sci. Part B, 44, 413 (2005).

10. a) A. D. Schwab, D. M. G. Agra, J. H. Kim, S. Kumar, and A. Dhinojwala, Macromolecules, 33, 4903 (2000).

b) D. M. G. Agra, A. D. Schwab, J. H. Kim, S. Kumar, and A. Dhinojwala, Europhys. Lett., 51, 655 (2000).

c) A. D. Schwab and A. Dhinojwala, Phys. Rev. E, 67, 021802 (2003).

11. a) V. Zaporojtchenko, T. Strunskus, J. Erichsen, and F. Faupel, Macromolecules, 34, 1125 (2001).

b) J. Erichsen, J. Kanzow, U. Schürmann, K. Dolgner, K. Günther-Schade, T. Strunskus, V. Zaporojtchenko, and F. Faupel, Macromolecules, 371831 (2004).

12. T. Kerle, Z. Lin, H. C. Kim, and T. P. Russell, Macromolecules, 34, 3484 (2001).

13. a) D. Kawaguchi, K. Tanaka, A. Takahara, and T. Kajiyama, Macromolecules, 34, 6164 (2001).

b) D. Kawaguchi, K. Tanaka, T. Kajiyama, A. Takahara, and S. Tasaki, Macromolecules, 36, 1235 (2003).

14. a) W. E. Wallace, D. A. Fischer, K. Efimenko, W. L. Wu, and J. Genzer, Macromolecules, 34, 5081 (2001).

b) W. L. Wu, S. Sambasivan, C. Y. Wang, W. E. Wallace, J. Genzer, and D. A. Fischer, Eur. Phys. J. E, 12, 127 (2003).

15. V. N. Bliznyuk, H. E. Assender, and G. A. D. Briggs, Macromolecules, 35, 6613 (2002).

16. a) H. Fischer, Macromolecules, 35, 3592 (2002).

b) H. Fischer, Macromolecules, 38, 844 (2005).

17. a) J. H. Teichroeb and J. A. Forrest, Phys. Rev. Lett., 91, 016104 (2003).

b) J. S. Sharp, J. H. Teichroeb, and J. A. Forrest, Eur. Phys. J. E, 15, 473 (2004).

c) Z. Fakhraai and J. A. Forrest, Phys. Rev. Lett., 95, 025701 (2005).

18. R. Weber, I. Grotkopp, J. Stettner, M. Tolan, and W. Press, Macromolecules, 36, 9100 (2003).

19. T. Sasaki, A. Shimizu, T. H. Mourey, C. T. Thurau, and M. D. Ediger, J. Chem. Phys., 119, 8730 (2003).

20. F. L. Pratt, T. Lancaster, M. L. Brooks, S. J. Blundell, T. Prokscha, E. Morenzoni, A. Suter, H. Luetkens, R. Khasanov, R. Scheuermann, U. Zimmermann, K. Shinotsuka, and H. E. Assender, Phys. Rev. B, 72, 121401 (2005).

21. a) G. Reiter, Europhys. Lett., 23, 579 (1993). b) G. Reiter, Macromolecules, 27, 3046 (1994).

22. a) J. L. Keddie, R. A. L. Jones, and R. A. Cory, Europhys. Lett., 27, 59 (1994).

b) S. Kawana and R. A. L. Jones, Phys. Rev. E, 63, 021501 (2001).

c) S. Kawana and R. A. L. Jones, Eur. Phys. J. E, 10, 223 (2003).

23. a) J. A. Forrest, K. Dalnoki-Veress, J. R. Stevens, and J. R. Dutcher, Phys. Rev. Lett., 77, 2002 (1996).

b) J. A. Forrest, K. Dalnoki-Veress, and J. R. Dutcher, Phys. Rev. E, 56, 5705 (1997).

c) J. A. Forrest and J. Mattsson, Phys. Rev. E, 61, R53 (2000).

d) J. S. Sharp, J. H. Teichroeb, and J. A. Forrest, Phys. Rev. Lett., 91, 235701 (2003).

24. a) K. L. Ngai, A. K. Rizos, and D. J. Plazek, J. Non-Cryst. Solids, 235, 435 (1998).

b) K. L. Ngai, Eur. Phys. J. E, 8, 225 (2002).

c) K. L. Ngai, Eur. Phys. J. E, 12, 93 (2003).

d) K. L. Ngai, T. R. Gopalakrishnan, and M. Beiner, Polymer, 47, 7222 (2006).

e) K. L. Ngai, J. Polym. Sci., Part B: Polym. Phys., 44, 2980 (2006).

25. a) K. Fukao and Y. Miyamoto, Europhys. Lett., 46, 649 (1999).

b) K. Fukao and Y. Miyamoto, Phys. Rev. E, 61, 1743 (2000).

c) K. Fukao and Y. Miyamoto, Phys. Rev. E, 64, 011803 (2001).

26. a) D. S. Fryer, P. F. Nealey, and J. J. de Pablo, Macromolecules, 33, 6439 (2000).

b) J. A. Torres, P. F. Nealey, and J. J. de Pablo, Phys. Rev. Lett., 85, 3221 (2000).

c) K. Yoshimoto, T. S. Jain, P. F. Nealey, and J. J. de Pablo, J. Chem. Phys., 122, 144712 (2005).

27. a) O. K. C. Tsui and H. F. Zhang, Macromolecules, 34, 9139 (2001).

b) F. Xie, H. F. Zhang, F. K. Lee, B. Du, O. K. C. Tsui, Y. Yokoe, K. Tanaka, A. Takahara, T. Kajiyama, and T. He, Macromolecules, 35, 1491 (2002).

28. a) C. J. Ellison, S. D. Kim, D. B. Hall, and J. M. Torkelson, Eur. Phys. J. E, 8, 155 (2002).

b) C. J. Ellison and J. M. Torkelson, Nat. Mater., 2, 695 (2003).

c) C. J. Ellison, M. K. Mundra, and J. M. Torkelson, Macromolecules, 38, 1767 (2005).

29. a) T. Kanaya, T. Miyazaki, H. Watanabe, K. Nishida, H. Yamano, S. Tasaki, and D. B. Bucknall, Polymer, 44, 3769 (2003).

b) T. Miyazaki, K. Nishida, and T. Kanaya, Phys. Rev. E, 69, 022801 (2004).

c) T. Miyazaki, K. Nishida, and T. Kanaya, Phys. Rev. E, 69, 061803 (2004).

d) R. Inoue, T. Kanaya, T. Miyazaki, K. Nishida, I. Tsukushi, and K. Shibata, Mater. Sci. Eng., A, 442, 367 (2006).

30. N. Tomczak, R. A. L. Vallée, E. M. H. P. van Dijk, L. Kuipers, N. F. van Hulst, and G. J. Vansco, J. Am. Chem. Soc., 126, 4748 (2004). 
31. a) K. Tanaka, Y. Tateishi, and T. Nagamura, Macromolecules, 37, 8188 (2004).

b) K. Akabori, K. Tanaka, T. Nagamura, A. Takahara, and T. Kajiyama, Macromolecules, 38, 9735 (2005).

32. M. Hamdorf and D. Johannsmann, J. Chem. Phys., 112, 4262 (2000).

33. a) S. Ge, W. Zhang, M. Rafailovich, J. Sokolov, C. Buenviaje, R. Buckmaster, and R. M. Overney, Phys. Rev. Lett., 85, 2340 (2000).

b) Y. Pu, S. Ge, M. Rafailovich, J. Sokolov, Y. Duan, E. Pearce, V. Zaitsev, and S. A. Schwarz, Langmuir, 17, 5865 (2001).

c) Y. Pu, M. H. Rafailovich, J. Sokolov, D. Gersappe, T. Peterson, W. L. Wu, and S. A. Schwarz, Phys. Rev. Lett., 87, 206101 (2001).

34. R. Weber, K. M. Zimmermann, M. Tolan, J. Stettner, W. Press, O. H. Seeck, J. Erichsen, V. Zaporojtchenko, T. Strunskus, and F. Faupel, Phys. Rev. E, 64, 061508 (2001).

35. a) M. Y. Efremov, J. T. Warren, E. A. Olson, M. Zhang, A. T. Kwan, and L. H. Allen, Macromolecules, 35, 1481 (2002)

b) M. Y. Efremov, E. A. Olson, M. Zhang, Z. Zhang, and L. H. Allen, Phys. Rev. Lett., 91, 085703 (2003).

c) M. Y. Efremov, E. A. Olson, M. Zhang, Z. Zhang, and L. H. Allen, Macromolecules, 37, 4607 (2004).

36. N. G. McCrum, B. E. Read, and G. Williams, "Anelastic and Dielectric Effects in Polymeric Solids," Dover, New York, 1967.

37. J. L. Keddie, R. A. L. Jones, and R. A. Cory, Faraday Discuss., 98, 219 (1994).

38. O. Prucker, S. Christian, H. Bock, J. Rühe, C. W. Frank, and W. Knoll, Macromol. Chem. Phys., 199, 1435 (1998).

39. a) K. Fukao, S. Uno, Y. Miyamoto, A. Hoshino, and H. Miyaji, Phys. Rev. E, 64, 051807 (2001).

b) K. Fukao, Eur. Phys. J. E, 12, 119 (2003).

c) K Fukao and A. Sakamoto, Phys. Rev. E, 71, 041803 (2005).

d) K. Fukao, A. Sakamoto, Y. Kubota, and Y. Saruyama, J. Non-Cryst. Solids, 351, 2678 (2005).

40. L. Hartmann, W. Gorbatschow, J. Hauwede, and F. Kremer, Eur. Phys. J. E, 8, 145 (2002).

41. J. S. Sharp and J. A. Forrest, Phys. Rev. E, 67, 031805 (2003).

42. a) C. B. Roth and J. R. Dutcher, Eur. Phys. J. E, 12, S103 (2003).

b) M. Wübbenhorst, C. A. Murray, and J. R. Dutcher, Eur. Phys. J. E, 12, S109 (2003).

c) C. B. Roth, A. Pound, S. W. Kamp, C. A. Murray, and J. R. Dutcher, Eur. Phys. J. E, 20, 441 (2006).
43. a) E. K. Lin, W. L. Wu, and S. K. Satija, Macromolecules, 30, 7224 (1997).

b) E. K. Lin, R. Kolb, S. K. Satija, and W. L. Wu, Macromolecules, 32, 3753 (1999).

44. a) Y. Grohens, M. Brogly, C. Labbe, M. O. David, and J. Schultz, Langmuir, 14, 2929 (1998).

b) Y. Grohens, L. Hamon, G. Reiter, A. Soldera, and Y. Holl, Eur. Phys. J. E, 8, 217 (2002).

45. a) C. E. Porter and F. D. Blum, Macromolecules, 33, 7016 (2000).

b) B. Zhang and F. D. Blum, Macromolecules, 36, 8522 (2003).

46. R. D. Priestley, C. J. Ellison, L. J. Broadbelt, and J. M. Torkelson, Science, 309, 456 (2005).

47. Y. Grohens, M. Brogly, C. Labbe, and J. Schultz. Eur. Polym. J., 33, 691 (1997).

48. O. N. Tretinnikov, Langmuir, 13, 2988 (1997).

49. D. Atack and D. Tabor, Proc. R. Soc., A246, 539 (1958).

50. K. Minato and T. Takemura, Jpn. J. Appl. Phys., 6, 719 (1967).

51. T. Kajiyama, K. Tanaka, and A. Takahara, Macromolecules, 30, 280 (1997).

52. Since the temperature at which the lateral force was maximized, was dependent on the measurement frequency, the temperature dependence of the relaxation time could be determined. Fitting the data using the Vogel-Fulcher equation gave a rough estimate for $T_{\mathrm{g}} \mathrm{s}$ of $325 \mathrm{~K}$.

53. The bulk $\beta$-process for it-PMMA could not be clearly seen at the frequency of $70 \mathrm{~Hz}$ because of overlap with the $\alpha_{\mathrm{a}^{-}}$ process. However, when the dynamic mechanical analysis was made at a lower frequency, bulk $\beta$-process was clearly observed. Thus, we extrapolated the $\beta$-relaxation temperature based on the Arrhenius equation.

54. a) K. Schmidt-Rohr, A. S. Kulik, H. W. Beckham, A. Ohlemacher, U. Pawelzik, C. Boeffel, and H. W. Spiess, Macromolecules, 27, 4733 (1994).

b) A. S. Kulik, H. W. Beckham, K. Schmidt-Rohr, D. Radloff, U. Pawelzik, C. Boeffel, and H. W. Spiess, Macromolecules, 27, 4746 (1994).

c) S. C. Kuebler, D. J. Schaefer, C. Boeffel, U. Pawelzik, and H. W. Spiess, Macromolecules, 30, 6597 (1997).

55. J. L. Koenig, in "Spectroscopy of Polymers," Elsevier, New York, 1999.

56. O. N. Tretinnikov and K. Ohta, Macromolecules, 35, 7343 (2002).

57. A. Soldera and Y. Grohens, Macromolecules, 35, 722 (2002).

58. H. Nagai, J. Appl. Polym. Sci., 7, 1697 (1963). 